\title{
EDITORIAL
}

\section{LADY HEALTH WORKERS PROGRAM IN PAKISTAN}

\author{
Iftikhar Ahmad \\ Department of Community Medicine, Gomal Medical College, D.I.Khan, Pakistan
}

Being signatory to Alma Ata declaration, the Government of Pakistan started the 'National Program for Family Planning and Primary Health Care' (NPFP \& PHC), also called 'Lady Health Workers (LHWs) program' in 1994. Being one of the largest and successful, community-based program in the world, it is providing door-step PHC services to about one billion people, especially home-bound, rural, poor women, children and elderly. The program has been improving many health indicators including infant and maternal mortality rates in the last two \& a half decades. ${ }^{1}$

The objective of this program is to extend the nation-wide outreach services to the communities through more than a hundred thousand locally trained LHWs in a phase-wise manner. One LHW is supposed to cater for 150 homes or 1000 people. The program is covering all the eight elements of $\mathrm{PHC}$ under the guidance of $\mathrm{PHC}$ principles of equity, community participation, appropriate technology and inter-sectorial coordination to bridge the gap between the community and health care system (HCS). ${ }^{1}$

The strengths and weaknesses of any program are important to assess. SWOT stands for strengths, weaknesses, opportunities, and threats. It is a management tool that can identify the strengths and weaknesses of any organization and opportunities and threats of the external environment. It can assess how a program is going on. ${ }^{2}$

The major strengths of the LHWs program include: adequate political commitment, rapid and transparent recruitment procedures, $60-70 \%$ coverage, ade- quate integration with HCS, proper management and supervision, provision of comprehensive healthcare with support of Management Information System, evidence-based improvement in health indicators and cost effective service. The LHWs working spirit within established community norms in creative ways and community involvement are the additional strengths. Their work is widely appreciated by most of the households. ${ }^{3}$

Weaknesses include poor management and integration at lower levels, contractual nature of the job, delayed/ low salaries despite protests, overwork due to involvement in multiple programs, weak supplies, weak referral systems and lower impact on certain targets. Besides, lack of funds and poor career development are the additional demotivating factors. ${ }^{1,4}$ Opportunities include wide coverage, social transformation in health-seeking behaviors of the community, trained workforce availability for other chores, the ability for emergency obstetrical care training, data support for research, leadership for women empowerment and poverty alleviation strategies. ${ }^{1,5}$

Threats include socio-cultural factors of male-controlled norms and caste-based village hierarchies constraining women to access to HCS on one hand and lowering LHWs status and home-visit rates on the other. Besides non-acceptance by doctors, paramedics and nurses, quackery temptations in LHWs is another identified threat. ${ }^{1}$

In conclusion, despite the LHW program showing good prospects to improve the health status of the communities, the weaknesses have to be removed to

KEY WORDS: Lady health worker; Health care system; Primary Health Care; House Calls; Management Information Systems; Family Planning Services; Comprehensive Health Care; Pakistan.

This article may be cited as: Ahmad I. Lady Health Workers program in Pakistan [editorial]. Gomal J Med Sci 2019: 17(4): 105-6. https://doi.org/10.46903/gjms/17.04.2094

\section{Corresponding Author:}

Professor Iftikhar Ahmad

Department of Community Medicine

Gomal Medical College

D.I.Khan, Pakistan.

E-mail: iftikharahmadgandapur@yahoo.com

Date Submitted: 23-03-2019

Date Revised: $\quad 18-05-2019$

Date Accepted: $\quad$ 01-06-2019 take the best output. More integration into the existing health care system through proper management will go a great deal in expanding the service delivery. Providing opportunities for professional development will dilute the stereo-typed socio-cultural influence by boosting the motivation of LHWs.

\section{REFERENCES}

1. Wazir MS, Shaikh BT, Ahmed A. National program for family planning and primary health care 
Pakistan: a SWOT analysis. Reprod Health 2013; 10: 60. https://doi.org/10.1186/1742-4755-10-60

2. Mumtaz Z, Salway S, Nykiforuk C, Bhatti A, Ataullahjan A, Ayyalasomayajula B. The role of social geography on Lady Health Workers' mobility and effectiveness in Pakistan. Soc Sci Med 2013; 91:48-57. https://doi.org/10.1016/j. socscimed.2013.05.007

3. Oliver M, Geniets A, Winters N, Rega I, Mbae SM. What do community health workers have to say about their work, and how can this inform improved programme design? A case study with
CHWs within Kenya. Glob Health Action 2015; 8: 27168. https://doi.org/10.3402/gha.v8.27168

4. Haq Z, Hafeez A. Knowledge and communication needs assessment of community health workers in developing countries: a qualitative study. Hum Res Health 2009;7:59. https://doi. org/10.1186/1478-4491-7-59

5. Hafeez A, Mohamud BK, Sheikh MR, Shah SAI, Jooma R. Lady health workers programme in Pakistan: challenges, achievements and the way forward. J Pak Med Assoc 2011; 61: 210-15.

CONFLICT OF INTEREST
Authors declare no conflict of interest.
GRANT SUPPORT AND FINANCIAL DISCLOSURE
None declared.
ed use, distribution \& reproduction in any medium provided that original work is cited properly. 